\title{
Toward an Integrated Seasonal Forecasting System for South America
}

\author{
C. A. S. Coelho and D. B. Stephenson \\ Department of Meteorology, University of Reading, Reading, United Kingdom \\ M. Balmaseda and F. J. Doblas-Reyes \\ European Centre for Medium-Range Weather Forecasts, Reading, United Kingdom \\ G. J. VAN OLDENBORGH \\ Royal Dutch Meteorological Institute, De Bilt, Netherlands
}

(Manuscript received 5 May 2005, in final form 17 November 2005)

\begin{abstract}
This study proposes an objective integrated seasonal forecasting system for producing well-calibrated probabilistic rainfall forecasts for South America. The proposed system has two components: (i) an empirical model that uses Pacific and Atlantic sea surface temperature anomalies as predictors for rainfall and (ii) a multimodel system composed of three European coupled ocean-atmosphere models. Three-month lead austral summer rainfall predictions produced by the components of the system are integrated (i.e., combined and calibrated) using a Bayesian forecast assimilation procedure. The skill of empirical, coupled multimodel, and integrated forecasts obtained with forecast assimilation is assessed and compared. The simple coupled multimodel ensemble has a comparable level of skill to that obtained using a simplified empirical approach. As for most regions of the globe, seasonal forecast skill for South America is low. However, when empirical and coupled multimodel predictions are combined and calibrated using forecast assimilation, more skillful integrated forecasts are obtained than with either empirical or coupled multimodel predictions alone. Both the reliability and resolution of the forecasts have been improved by forecast assimilation in several regions of South America. The Tropics and the area of southern Brazil, Uruguay, Paraguay, and northern Argentina have been found to be the two most predictable regions of South America during the austral summer. Skillful rainfall forecasts are generally only possible during El Niño or La Niña years rather than in neutral years.
\end{abstract}

\section{Introduction}

South American seasonal forecasts are currently produced with either empirical (statistical) or physically derived dynamical models (see brief literature review in section 2). The need for an objective method for combining different pieces of available forecast information in South America has recently been recognized by Berri and Antico (2005). This paper addresses and proposes a solution for this problem by objectively producing a single integrated (i.e., combined and calibrated) forecast of seasonal rainfall for South America that

Corresponding author address: Dr. C. A. S. Coelho, Department of Meteorology, University of Reading, Earley Gate, P.O. Box 243, Reading RG6 6BB, United Kingdom.

E-mail: c.a.d.s.coelho@reading.ac.uk gathers prediction information from four different sources (three coupled ocean-atmosphere models and an empirical model).

Good quality seasonal forecasts with reliable uncertainty estimates are fundamental for governments to plan actions in order to minimize human and economical losses that may be caused by anomalous climate events, such as those observed during El NiñoSouthern Oscillation (ENSO) episodes. In South America, seasonal forecasts are used for planning civil defense, agricultural, fishery, and water resources (reservoir management). Brazil, the largest and most populated country of South America, produces more than $90 \%$ of its electricity from hydropower stations, emphasizing the need for reliable seasonal rainfall forecasts (see online at http://www.ons.org.br). The provision of improved seasonal rainfall forecasts could help the Bra- 
a) Annual mean

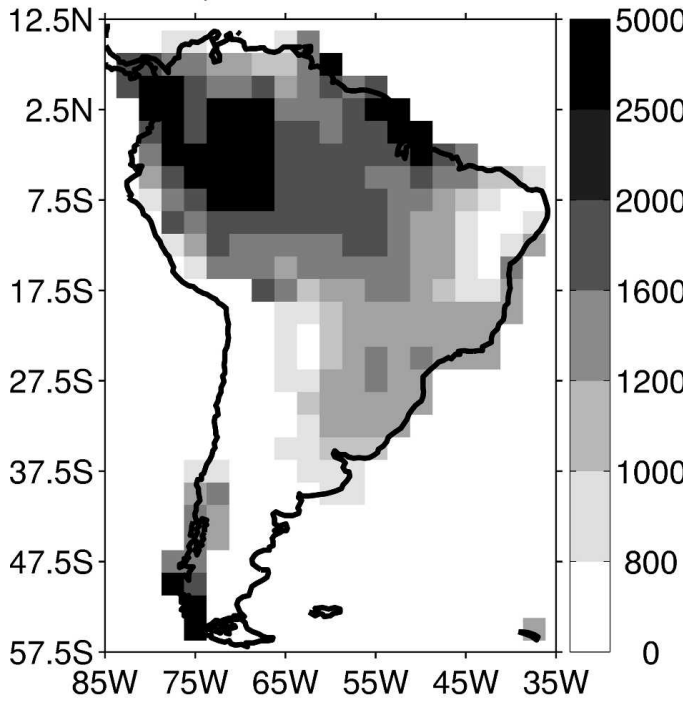

c) Annual standard deviation

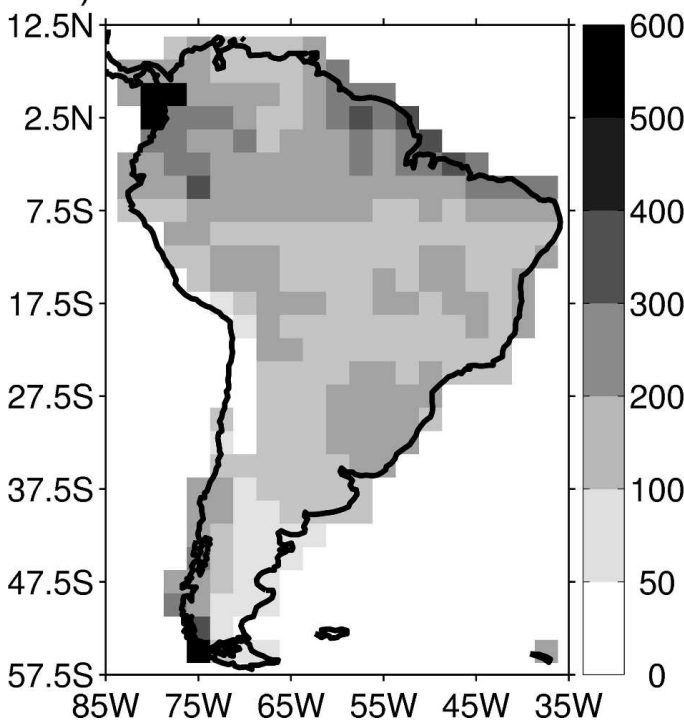

b) NDJ mean

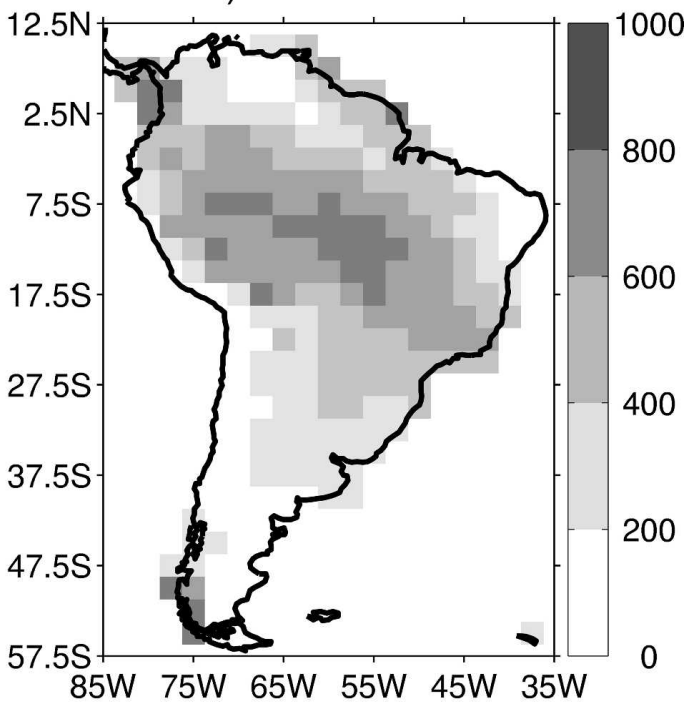

d) NDJ standard deviation

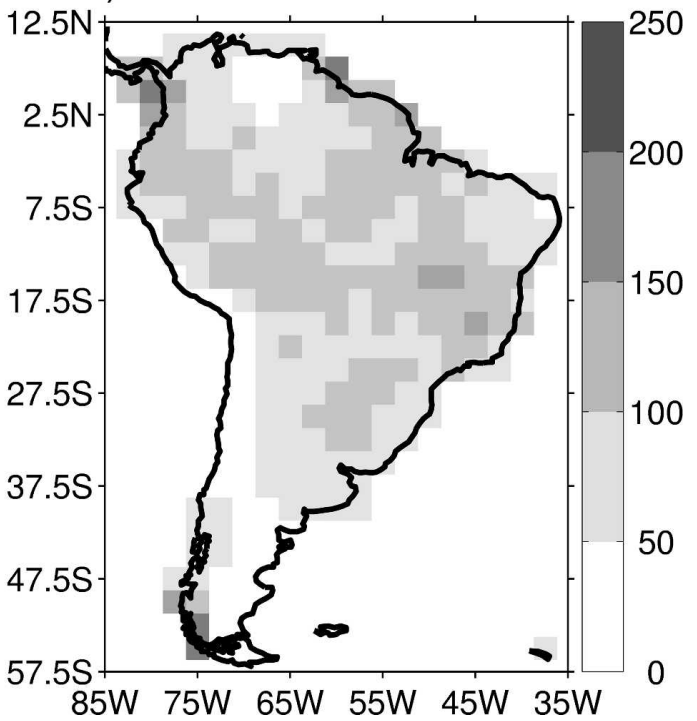

FIG. 1. Total (a) annual mean rainfall, (b) NDJ mean rainfall, (c) annual rainfall standard deviation, and (d) NDJ rainfall standard deviation. Units are in $\mathrm{mm}$. The climatological reference is 1948-2001 and the source is Chen et al. (2002).

zilian government to better plan its management actions in order to have more efficient control of its national electricity production program.

Figure 1a shows the total annual mean rainfall for South America obtained from the 50-yr 1948-2001 global monthly precipitation reconstruction over land (PREC/L) version 1.0 dataset (Available online at ftp:// ftp.cpc.ncep.noaa.gov/precip/50yr/gauge/2.5deg/; Chen et al. 2002), which is based on gauge observations. The accuracy of this rainfall dataset over South America is reasonably good and comparable to the accuracy of the
Global Precipitation Climatology Project (GPCP) dataset (Huffman et al. 1997). Figure 1b shows the mean rainfall in austral summer [November-January (NDJ)]. A large fraction of the total annual rainfall falls during the austral summer, which defines the wet season for most of South America. Tropical and southern South America have the largest interannual rainfall variability (Figs. 1c,d). Although good quality dry season forecasts may be as important as wet season forecasts for some sectors, wet season forecasts are of the most relevance for electricity generation. This study fo- 
a) La Nina

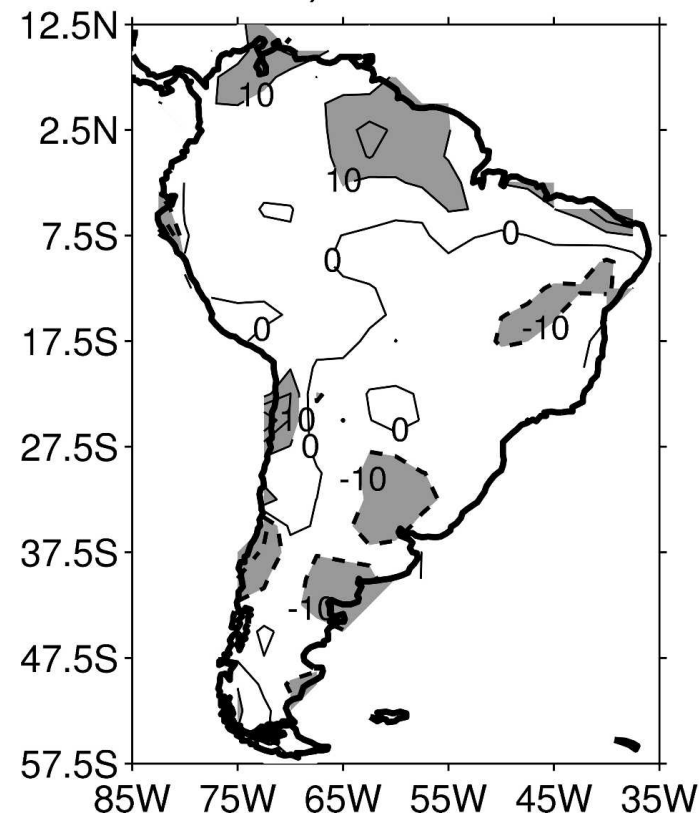

b) El Nino

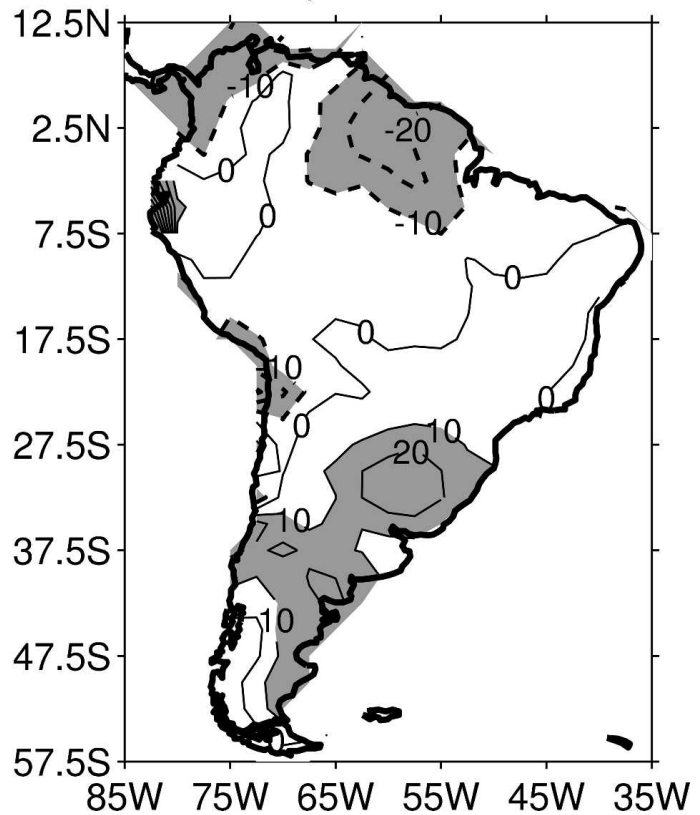

FIG. 2. NDJ (a) La Niña and (b) El Niño composites for those years listed in Table 1 of section 5. Composites are given by the quantity $\left.c=\left[\bar{y}_{*} / \bar{y}\right)-1\right] 100 \%$, where $\bar{y}_{*}$ is the mean NDJ rainfall of La Niña and El Niño years of Table 1 and $\bar{y}$ is the 1948-2001 mean NDJ rainfall. Regions with positive anomalies (i.e. $\bar{y}_{*}>\bar{y}$ ) have the quantity $c>0$. Regions with negative anomalies (i.e. $y_{*}<\bar{y}$ ) have the quantity $c<0$.

cuses on predictions of NDJ rainfall anomalies for South America produced with the initial conditions of the first day of the preceding August (i.e., a 3-month lead). These are the longest lead austral summer predictions that were available for investigation from the European Union-funded project entitled Development of a European Multimodel Ensemble System for Seasonal to Interannual Prediction [(DEMETER) see online at http://www.ecmwf.int/research/demeter; Palmer et al. 2004]. Three-month-lead, traditional austral summer December-February (DJF) forecasts could not be examined because DEMETER simulations have only been produced four times each year, starting on the first day of February, May, August, and November.

South America is a region that has strong atmospheric teleconnections with ENSO (Wallace and Gutzler 1981; Trenberth et al. 1998). Because of these teleconnections, there is promising skill in seasonal forecasts for some regions of South America. Figure 2 shows La Niña and El Niño composites of austral summer rainfall. These figures illustrate regions strongly affected during ENSO events (shaded areas). During La Niña years, positive anomalies are observed in northern South America and negative anomalies are observed in southern-southeastern South America. This pattern is reversed during El Niño years. During
El Niño years, an east-west dipole of positive anomalies near the coast of Peru and Ecuador and negative anomalies over northern South America are observed. A reverse dipole pattern is observed during La Niña years. Seasonal forecasts in these regions have some predictive skill, as will be discussed in more detail later.

Seasonal forecasts currently issued at coarse $2.5^{\circ}$ horizontal resolution are not able to (and are not expected to) simulate the observed climate perfectly. This problem is further aggravated by the lack of comprehensive observational datasets to initialize the models appropriately and the lack of a complete physical understanding of the climate system. All these limitations contribute to uncertainties in climate predictions and therefore, calibration against past observations is required. To our knowledge, no studies have been published with the aim of improving the quality of South American physically derived climate model seasonal predictions by statistical calibration based on past observations. Most previous studies (e.g., Cavalcanti et al. 2002; Marengo et al. 2003; Moura and Hastenrath 2004) investigated the ability of atmospheric general circulation models in simulating climatological features such as the annual and seasonal cycles of rainfall for some regions of South America. These studies have identi- 
fied systematic forecast errors, yet have not suggested approaches for correcting these errors so as to improve the forecasts. The errors arise from a combination of factors such as the chaotic evolution of the atmosphere, errors in the initial conditions of the model, and errors in model formulation/parameterization.

We present a new integrated rainfall seasonal forecasting system for South America that consists of an empirical model and a coupled multimodel ensemble prediction system. Integrated forecasts are produced using a probabilistic Bayesian forecast assimilation procedure (Coelho 2005; Stephenson et al. 2005). This procedure allows the production of well-calibrated reliable probability estimates of rainfall. It also allows the combination of empirical and coupled multimodel predictions. The resulting combined and calibrated forecasts are summarized by the mean and the variance of a normal (Gaussian) distribution at each grid point. A particular aim of this study is to answer the question of whether or not forecasts produced by the proposed integrated system are better than those produced by a simple empirical model or by the simple multimodel ensemble system alone.

Section 2 reviews the current state of South American rainfall seasonal forecasting. Section 3 briefly introduces and describes the two components of the proposed integrated system. Section 4 summarizes how predictions are objectively combined and calibrated in the proposed integrated system. The skill of combined and calibrated forecasts of the integrated system as well as of empirical and multimodel ensemble predictions alone are assessed and compared in section 5. Finally, section 6 concludes the paper with a summary of the major findings and a discussion of possible future areas of research.

\section{Brief review of South American rainfall seasonal forecasting}

Several studies (e.g., Folland et al. 2001; Cavalcanti et al. 2002; Marengo et al. 2003; Moura and Hastenrath 2004) have demonstrated that atmospheric models forced with observed sea surface temperatures have some predictive skill when forecasting rainfall in the tropical region of South America and over the southern part of Brazil, Uruguay, Paraguay, and northeastern Argentina-a region known as southeastern South America. All other areas of South America showed poor predictive skill. They all found that forecast skill is highly conditioned on the presence of ENSO events, with neutral years having less predictive skill. Both tropical and southeastern South America have strong ENSO signals (Fig. 2).
Studies by Pezzi et al. (2000), Folland et al. (2001), Greischar and Hastenrath (2000), and Martis et al. (2002) have developed empirical models that relate observed rainfall to both sea surface temperature over the Atlantic and Pacific Oceans and the meridional surface wind component over the tropical Atlantic. These models have been used to predict seasonal rainfall over the south and northeast regions of Brazil and the Netherlands Antilles because of the higher predictability of these regions compared to the other areas of South America (Cavalcanti et al. 2002; Marengo et al. 2003). Empirical predictions for the northeast region of Brazil are skillful during the period March-May (MAM), which is the rainy season for most parts of this region (Greischar and Hastenrath 2000; Folland et al. 2001; Moura and Hastenrath 2004). Empirical predictions of Pezzi et al. (2000) for the south of Brazil are generally less skillful than the predictions for the northeast region of Brazil, and El Niño years were found to be more predictable than neutral and La Niña years. The majority of these studies produced deterministic forecasts. Very little effort has been put into producing probabilistic rainfall seasonal forecasts for South America, emphasizing that this is an area of research that deserves further attention.

The comparative skill of physically derived dynamical and empirically based seasonal predictions of South American rainfall has not been fully explored, and further systematic comparisons are desirable (Moura and Hastenrath 2004). Van Oldenborgh et al. (2005) concluded that physically derived dynamical predictions slightly outperform empirical predictions over tropical South America, northeast Brazil, and Uruguay in DJF. Folland et al. (2001) and Moura and Hastenrath (2004) focused on rainfall forecasts for the northeast of Brazil and concluded that physically derived dynamical predictions do not outperform empirically based predictions. Their conclusions are in accordance with other comparative skill assessment studies for other target regions outside South America (e.g., Barnston et al. 1999; Anderson et al. 1999). Section 5 of this paper will contribute to this skill comparison exercise. We compare the skill of an empirical model that uses observed Pacific and Atlantic sea surface temperature anomalies to predict South American austral summer rainfall anomalies with the skill of 3-month lead austral summer rainfall anomaly predictions produced by a coupled multimodel ensemble for the period 19592001. The empirical model developed in this study differs from those of previous studies in that it predicts rainfall anomalies for the entire South American continent, while previous studies focused only on specific subregions. 
Combining the predictions from these two approaches can help yield better forecasts of future climate. The International Research Institute for Climate Prediction (IRI) subjectively combines physically derived dynamical and empirically based seasonal predictions for several continental regions (Barnston et al. 2003). Objective combination has still not been implemented operationally by any seasonal climate prediction center. This study demonstrates an objective forecast assimilation scheme for combining physically derived coupled model and empirically based predictions of South American rainfall anomalies. The skill of integrated forecasts obtained with forecast assimilation is shown to exceed the skill of each individual prediction approach.

\section{Empirical and coupled model predictions}

\section{a. Empirical prediction model}

Surface conditions of the Pacific and Atlantic Oceans are potential sources of predictability for the South American climate (Moura and Shukla 1981; Mechoso et al. 1990; Nobre and Shukla 1996; Diaz et al. 1998; Uvo et al. 1998; Barros and Silvestri 2002; Coelho et al. 2002; Paegle and Mo 2002, among others). These studies have identified South American regions where rainfall is sensitive to sea surface temperature anomalies in these two oceans. This section exploits these rainfallsea surface temperature relationships by using a lagged regression empirical model based on maximum covariance analysis (MCA; von Storch and Zwiers 1999), sometimes referred to as singular value decomposition (SVD). The empirical model uses May-July (MJJ) Pacific and Atlantic sea surface temperature anomalies $\left(15^{\circ} \mathrm{N}-60^{\circ} \mathrm{S} ; 140^{\circ}-10^{\circ} \mathrm{E}\right)$ as predictors for South American rainfall anomalies of the following NDJ time period during 1959-2001. The previous season, MJJ, is used for consistency with the initial conditions of the first day of August that are used by the three DEMETER coupled models here investigated to predict NDJ rainfall (see section $3 \mathrm{~b}$ ). In this way, both empirical and coupled models use initial conditions observed up until the last day of July. Sea surface temperature anomalies were obtained from the 40-yr European Centre for MediumRange Weather Forecasts (ECMWF) Re-Analysis (ERA-40; Uppala et al. 2005; more information available online at http://www.ecmwf.int/research/era/). Precipitation anomalies were obtained from PREC/L version 1.0 dataset (Chen et al. 2002). These datasets have been chosen because they are among the most complete with the longest records available for climate research.

A simple way to predict a South American rainfall anomaly $\mathbf{y}$ uses multivariate linear regression on the preceding sea surface temperature anomaly $\mathbf{z}$ :

$$
\mathbf{y}=\mathbf{M}\left(\mathbf{z}-\mathbf{z}_{0}\right)+\boldsymbol{\varepsilon}_{\mathbf{T}},
$$

where $\mathbf{y}$ is a $q$-dimensional vector, $\mathbf{z}$ is a $p$-dimensional vector, $\mathbf{z}_{0}$ is a $p$-dimensional bias vector, $\mathbf{M}$ is a $p \times p$ matrix of parameters, and $\varepsilon_{\mathbf{T}}$ is a (multivariate) normally distributed error with zero mean and $q \times q$ error covariance matrix $\mathbf{T}$. The equation can be written as the following probability model:

$$
\mathbf{y} \mid \mathbf{z} \sim N\left[\mathbf{M}\left(\mathbf{z}-\mathbf{z}_{0}\right), \mathbf{T}\right],
$$

where the standard statistical symbol | means given (conditional upon) and $\sim N[$.$] means normally distrib-$ uted (multivariate).

The normality assumption is generally valid for seasonal rainfall anomalies. Figure 3a shows the YuleKendall skewness statistics for seasonal mean rainfall anomalies. These statistics provide a resistant measure of asymmetry of the distribution that is defined as

$$
\gamma=\frac{y_{0.25}-2 y_{0.5}+y_{0.75}}{y_{0.75}-y_{0.25}},
$$

where $y_{0.25}, y_{0.5}$, and $y_{0.75}$ are the lower, median, and upper quartiles of the observed or predicted rainfall anomalies at each grip point, respectively. Several regions of South America have $\gamma$ close to zero, indicating that seasonal mean rainfall anomalies for these regions are closely approximated by a normal distribution. The normality assumption substantially simplifies both modeling and parameter estimation.

The matrices $\mathbf{M}$ and $\mathbf{T}$ and the bias vector $\mathbf{z}_{0}$ can be obtained using ordinary least squares estimation:

$$
\begin{aligned}
\hat{\mathbf{M}} & =\mathbf{S}_{y z} \mathbf{S}_{z z}^{-1}, \\
\hat{\mathbf{T}} & =\mathbf{S}_{y y}-\mathbf{S}_{y z} \mathbf{S}_{z z}^{-1} \mathbf{S}_{y z}^{\mathrm{T}}, \\
\hat{\mathbf{z}}_{0} & =-\left(\overline{\mathbf{y}}-\overline{\mathbf{z}} \mathbf{M}^{\mathrm{T}}\right) \mathbf{M}\left(\mathbf{M}^{\mathrm{T}} \mathbf{M}\right)^{-1},
\end{aligned}
$$

where $\mathbf{S}_{z z}$ is the $(p \times p)$ covariance matrix of sea surface temperature anomalies, $\mathbf{S}_{y y}$ is the $(q \times q)$ covariance matrix of rainfall anomalies, and $\mathbf{S}_{y z}$ is the $(q \times p)$ cross-covariance matrix. Overbars denote the time means of $\mathbf{y}$ and $\mathbf{z}, \mathbf{X}^{\mathrm{T}}$ denotes the transpose of matrix $\mathbf{X}$, and $\mathbf{X}^{-1}$ denotes the inverse of matrix $\mathbf{X}$. The common period of rainfall and sea surface temperature anomalies used for estimation in this study is 1959-2001 $(n=$ 43 summers).

Reliable parameter estimation is difficult because of the large dimensionality of gridded datasets (e.g., $p=$ 2761 grid points of sea surface temperature anomalies over the Pacific and Atlantic and $q=312$ grid points of rainfall anomalies over South America) and the strong dependency between values at neighboring grid points. 
a) Observation

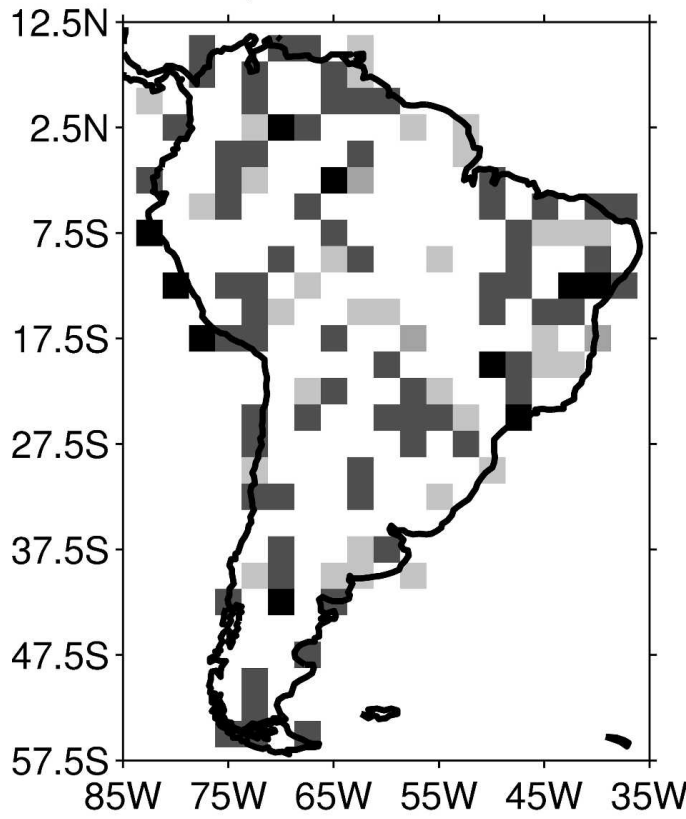

c) ECMWF

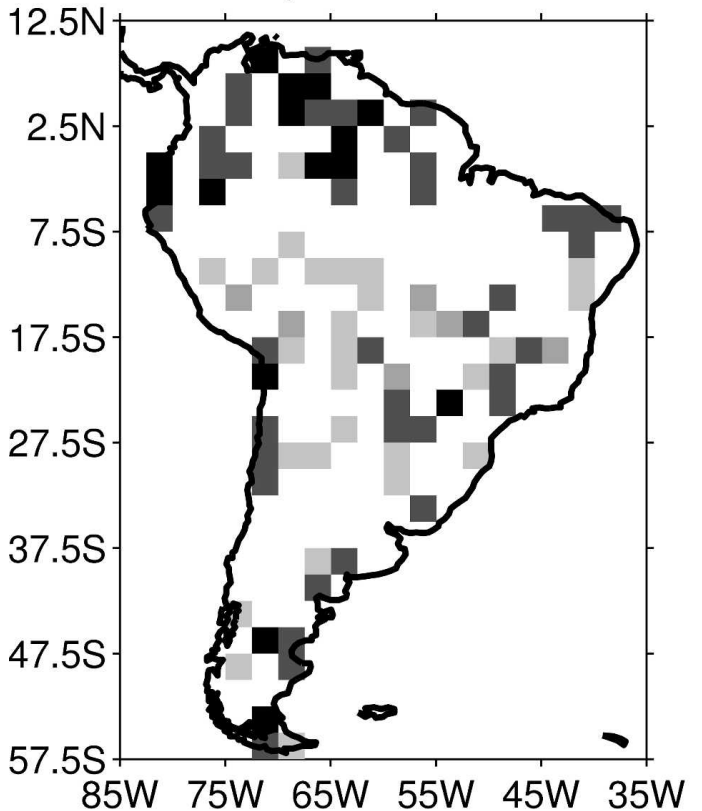

b) CNRM

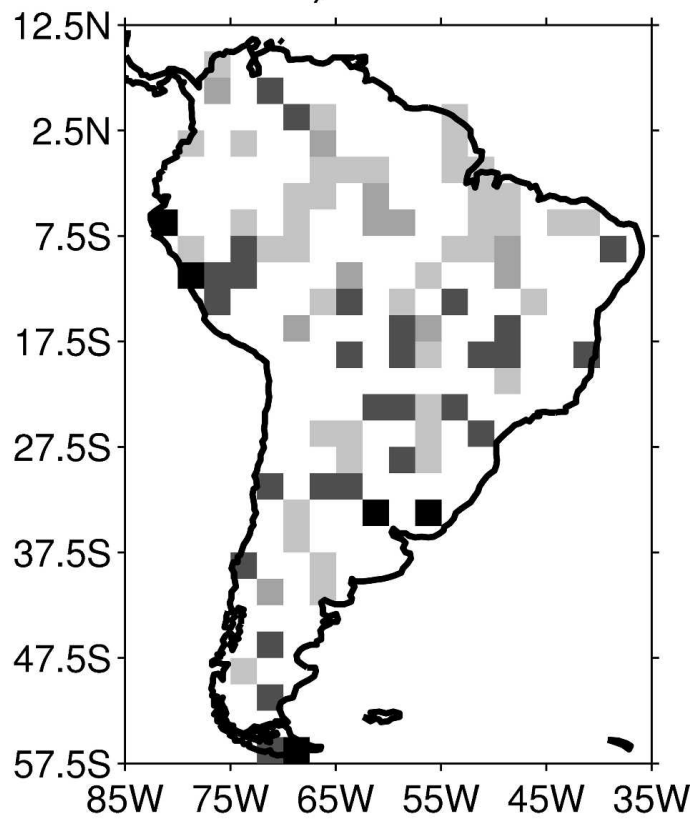

d) UKMO

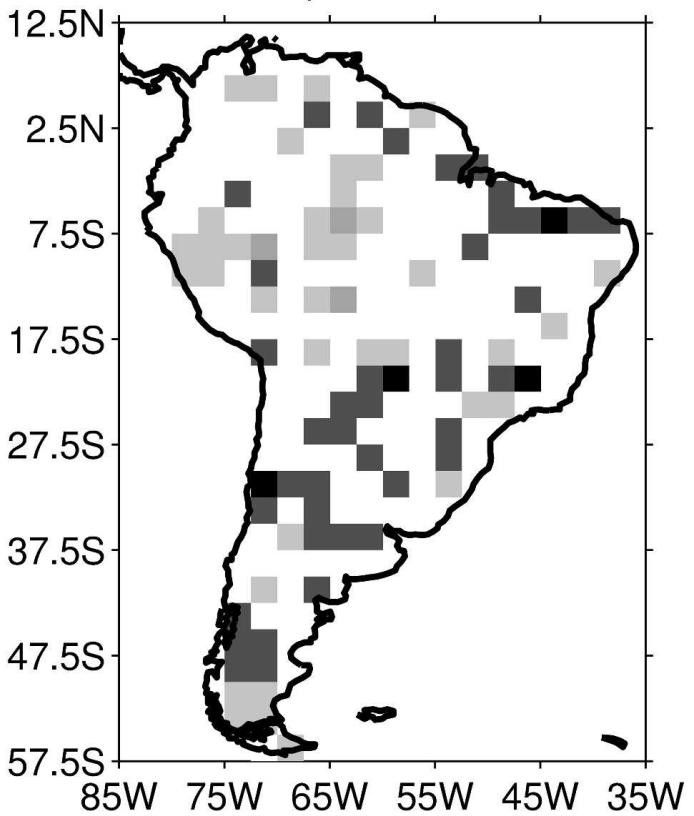

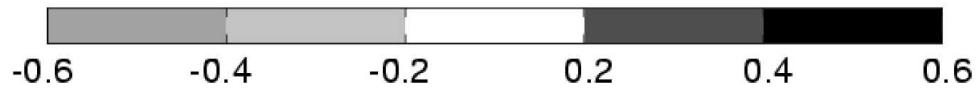

FIG. 3. NDJ 1959-2001 Yule-Kendall skewness statistics $\gamma$ of rainfall anomalies. (a) Observations, (b) CNRM, (c) ECMWF, and (d) UKMO coupled model predictions.

Poor conditioning of matrices such as $\mathbf{S}_{z z}$ makes parameter estimation unreliable. This problem can be circumvented using multivariate dimension reduction techniques to reduce the dimensionality of the datasets.
Instead of considering grid point variables, one can project the data onto a small set of leading spatial patterns to obtain a small number of indices. In the example presented here, MCA has been used to extract 


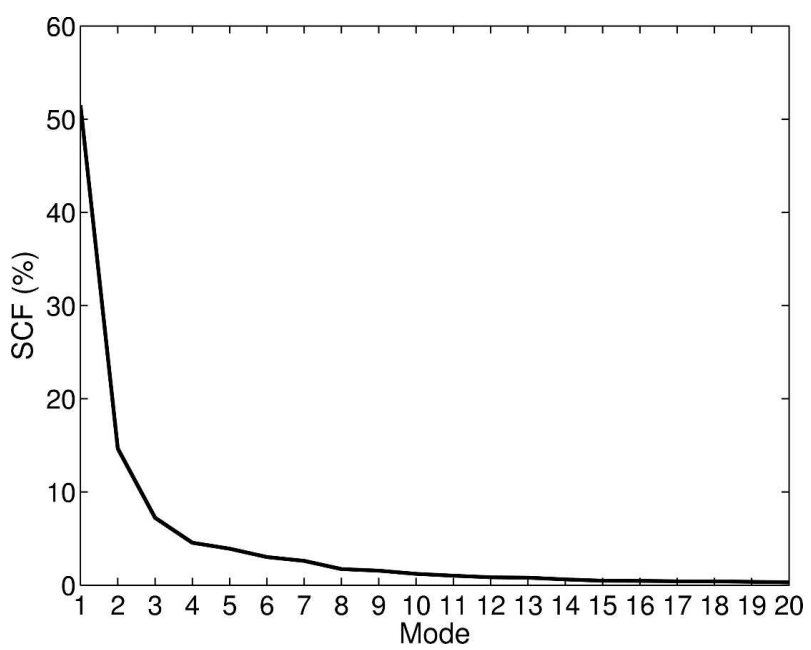

FIG. 4. SCF as a function of the number of modes for the MCA between observed MJJ SST and observed NDJ South American rainfall anomalies for the period 1959-2001. The first six modes account for $84.8 \%$ of the covariance between observed SST and rainfall anomalies.

leading covarying modes of sea surface temperature and rainfall anomalies. A large number of MCA modes have been retained and tested. It was found that MCA with six modes gave the best cross-validated forecast results, which are hereafter shown in this paper. The first six modes account for $84.8 \%$ of the squared covariance between sea surface temperature and rainfall anomalies. Figure 4 shows the squared covariance fraction (SCF) as a function of the number of modes for the MCA between sea surface temperature and rainfall anomalies. The SCF drops monotonically until six modes. After six modes, a very small amount of the squared covariance is accounted for by each additional MCA mode.

Figure 5 shows correlation maps (spatial patterns) and the expansion coefficients (time series) of the first mode of the MCA analysis between sea surface temperature anomalies and South American rainfall anomalies over the period 1959-2001. Correlation maps are obtained by correlating the expansion coefficient time series of one field (e.g., rainfall) with the observed grid point values of the other field (e.g., sea surface temperature). Correlations with magnitude $>0.3$ are statistically significant at the $5 \%$ level using a two-sided Student's $t$ test. This first mode accounts for $51.5 \%$ of the squared covariance between sea surface temperature and rainfall. The sea surface temperature pattern (Fig. 3a) shows basinwide correlations in the equatorial Pacific related to ENSO. Warm (El Niño) years are evident as positive peaks in the time series in Fig. 5c and cold (La Niña) years are evident by minima in these time series. The rainfall pattern (Fig. 5b) has negative correlations over northern South America and positive correlations over southern Brazil, Uruguay, Paraguay, northern Argentina, and Ecuador. This figure reveals a dipole pattern that during El Niño years is marked by a deficit of rainfall in northern South America and an excess of rainfall in southeastern South America. During La Niña years, this pattern is reversed. Note the east-west dipole pattern between the coast of Peru and Ecuador and northern South America, which was also previously identified in Fig. 2. A similar ENSO pattern to Fig. 5 has been identified by Ropelewski and Halpert (1987), Kiladis and Diaz (1989), and Paegle and Mo (2002) and is in accordance with the ENSO composites shown in Fig. 2. The second and the third MCA modes (not shown) account for $14.7 \%$ and $7.2 \%$ of the squared covariance, respectively, and relate sea surface temperature variability in the Atlantic Ocean to rainfall over South America. The second mode has positive correlation between sea surface temperatures in the equatorial Atlantic and rainfall over the northeast region of Brazil. The third mode positively relates sea surface temperatures over a large area of the Atlantic with rainfall over central and northwestern South America.

The empirical predictions (EMP) are performed as follows:

1) To avoid artificial skill, the model parameters are estimated for each summer only using data for all of the other summers (cross-validation).

2) Time means are subtracted from the $(n-1)$ sea surface temperature and rainfall observations to make anomalies stored in a $(n-1 \times q)$ data matrix $\mathbf{Y}$ and a $(n-1 \times p)$ data matrix $\mathbf{Z}$, respectively.

3) An SVD analysis is performed on the matrix $\mathbf{Y}^{\mathrm{T}} \mathbf{Z}$ to determine the leading MCA modes $\mathbf{U}$ and $\mathbf{V}$ in $\mathbf{Y}^{\mathrm{T}} \mathbf{Z}$ $=\mathbf{U} \Sigma \mathbf{V}^{\mathrm{T}}$.

4) A multivariate regression of the $k$-leading MCA rainfall and sea surface temperature modes is performed in order to estimate $\mathbf{M}, \mathbf{z}_{0}$, and $\mathbf{T}$.

5) The estimated quantities $\mathbf{M}, \mathbf{z}_{0}$, and $\mathbf{T}$ are then used to predict the rainfall anomalies for the removed year using the sea surface temperature anomalies available for that year.

\section{b. Coupled multimodel ensemble predictions}

An ensemble forecast of an individual coupled model samples uncertainties in the initial conditions used to produce the forecast. Uncertainties in the model formulation are not sampled by this single-model ensemble approach. However, different models use different numerical and parameterization schemes to 
a) SST: Mode 1 SCF: $51.5 \%$

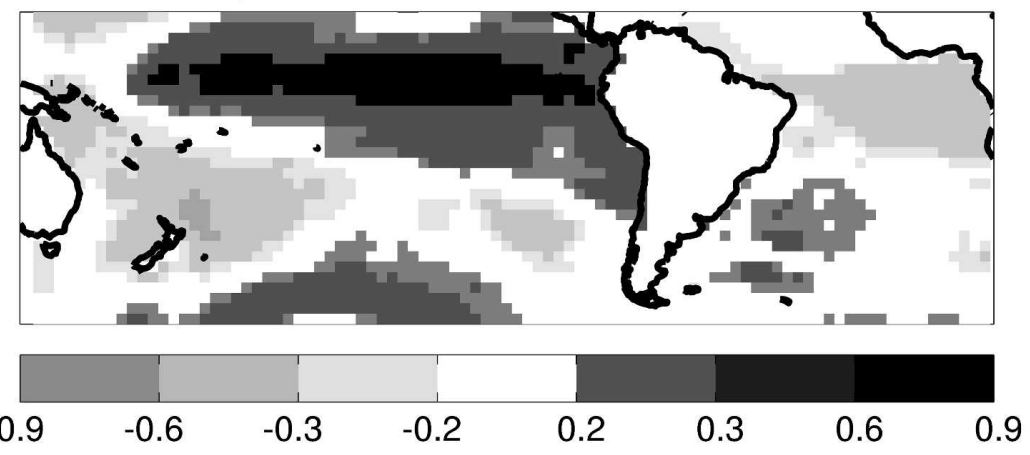

c) Time series $\quad r=0.84$ b) Precipitation

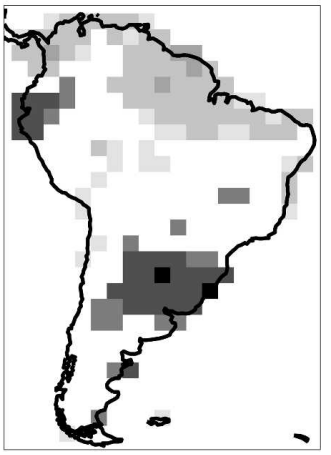

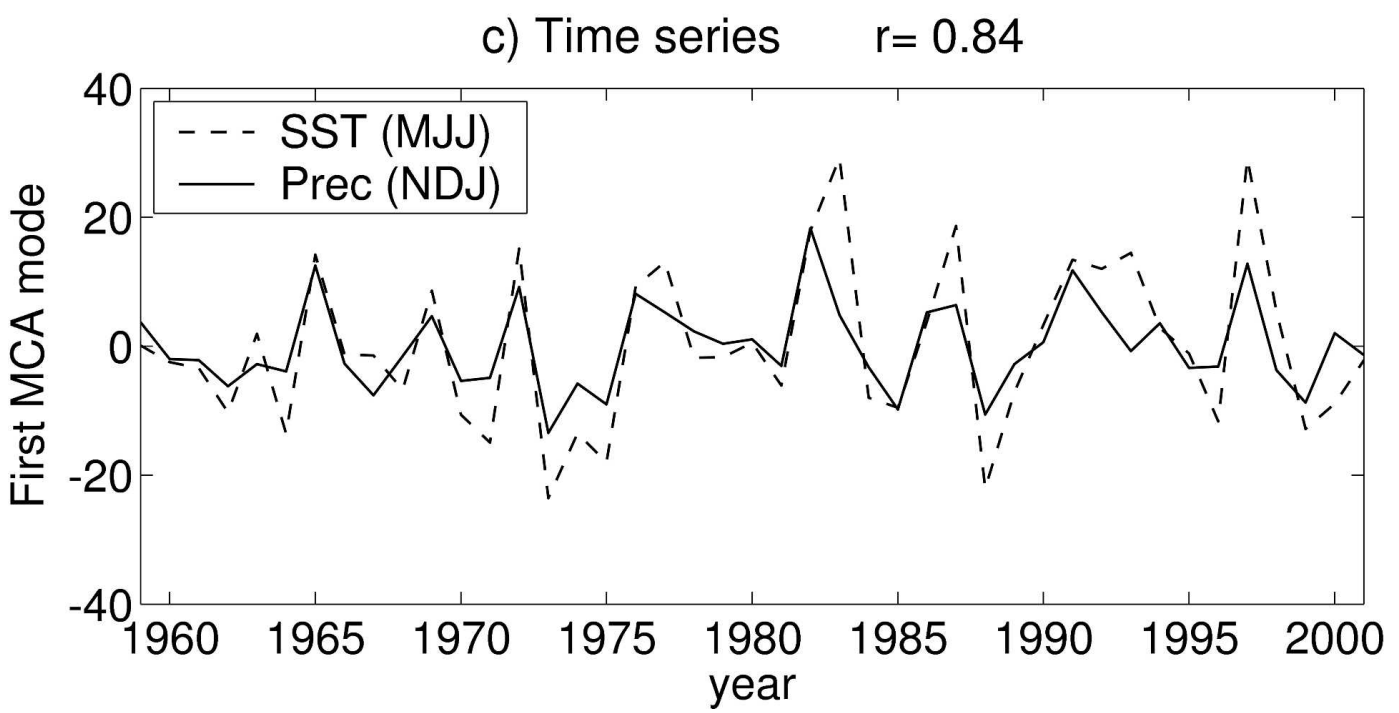

FIG. 5. First MCA mode between MJJ SST anomalies and NDJ South American rainfall anomalies for the period 1959-2001. The SCF, which indicates the percentage of the total squared covariance between the two anomalies explained by this mode, is $51.5 \%$. The correlation pattern of (a) SST and (b) rainfall. (c) Expansion coefficients (time series) of SST (dashed line) and rainfall (solid line). The correlation $r$ between these two time series is indicated in (c).

mathematically represent the same physical processes. The multimodel ensemble, consisting of ensemble predictions produced by different climate research institutions, helps sample uncertainties due to model formulation.

The multimodel forecasting system used here consists of the three state-of-the-art European coupled ocean-atmosphere models. The three models are the Météo-France Center National de Recherches Météorologiques (CNRM) model, ECMWF model, and United Kingdom Met Office (UKMO) model. These models were run as part of the DEMETER project at ECMWF (Palmer et al. 2004) to produce multimodel ensemble hindcasts (i.e., retrospective forecasts produced after the events are observed) for the period 1959-2001 (43 yr). In fact, a total of seven coupled models were run in DEMETER. The reason for only using predictions of three models is because the CNRM, ECMWF, and UKMO models produced the longest time series of hindcasts. The coupled models were run 4 times $\mathrm{yr}^{-1}$, starting on the first day of February, May, August, and November at 0000 UTC. A nine-member ensemble forecast was made for each coupled model for the following 6 months. Wind stress and sea surface temperature perturbations were used to generate the ensemble members for each model. Atmospheric and land surface initial conditions were taken from ERA40. Initial ocean conditions were taken from extended ocean-only integrations, where the different ocean models were forced by ERA-40 surface fluxes. All model predictions were bilinearly interpolated onto the same $2.5^{\circ} \times 2.5^{\circ}$ grid. More details of the experiments and model initialization procedures are described in Palmer et al. (2004) and Hagedorn et al. (2005). 
The 27-member ensemble of the three coupled models investigated here is used to produce predictions of austral summer rainfall for South America. These predictions are obtained by computing the ensemble mean and variance of all members of the ensemble and are referred to as coupled multimodel ensemble predictions (ENS) or, simply, multimodel predictions.

\section{Calibration and combination of forecasts}

The objective forecast assimilation procedure of Coelho (2005) and Stephenson et al. (2005) is used here for the calibration and combination of South American rainfall anomaly predictions produced by the CNRM, ECMWF, and UKMO coupled models and the empirical model of section 3a.

A useful feature of forecast assimilation is that it allows predicted patterns to be shifted spatially in order to correct for model biases in coupled model predictions. In other words, the procedure accounts for intergrid point dependencies, whereas the combination methods used by Rajagopalan et al. (2002), Mason and Mimmack (2002), and Robertson et al. (2004) are performed at grid points individually. The appendix summarizes the forecast assimilation procedure and describes three different forecast assimilation experiments examined. However, because of the superior forecast quality of one experiment [called integrated forecasts (INT)] compared to the other two experiments, only the results of the INT experiment will be presented and discussed.

Integrated forecasts are based on the MCA between observed and model predicted anomalies (see the appendix). The first three leading modes of the MCA between observed and model predictions of South American rainfall anomalies were used in the forecast assimilation procedure to produce integrated forecasts. A large number of modes was retained and tested. Forecast assimilation with three modes gave the best cross-validated forecast results. These three modes account for $87.8 \%$ of the squared covariance between observed and predicted rainfall. Figure 6 shows the SCF as a function of the number of modes. The SCF drops monotonically until three modes. After three modes, a very small amount of the squared covariance is accounted for by each additional MCA mode.

Figure 7 shows correlation maps (spatial patterns) and the expansion coefficients (time series) of the leading mode of the MCA between observed and model predicted South American rainfall anomalies. Correlation maps are obtained by correlating the prediction time series of expansion coefficients with the observed and predicted grid point values of each model. Correlations with magnitude greater than 0.3 are statistically

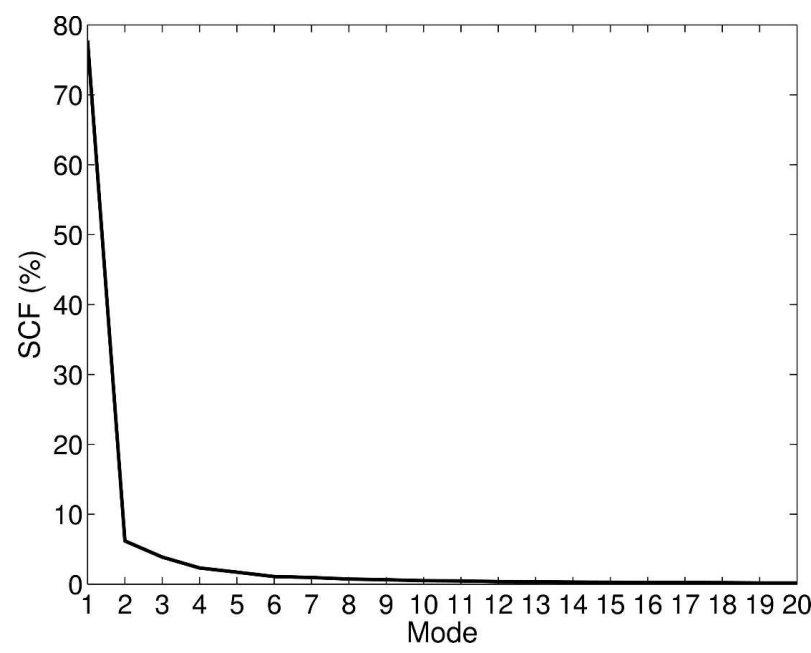

FIG. 6. SCF as a function of the number of modes for the MCA between observed and predicted austral summer South American rainfall anomalies for the period 1959-2001.

significant at the 5\% level using a two-sided Student's $t$ test. The leading mode accounts for $77.7 \%$ of the squared covariance between observed and predicted rainfall. The pattern of observed rainfall (Fig. 7a) is similar to the rainfall pattern of the first MCA mode in Fig. 5b, which is related to ENSO. The correlation between the expansion coefficients (time series) of observed rainfall of the first MCA mode (solid line in Fig. 7f) and the expansion coefficients (time series) of observed rainfall of the first MCA mode between MJJ SST anomalies and NDJ South American rainfall anomalies (solid line in Fig. 5c) is 0.98. This correlation is statistically significant at the $1 \%$ level using a twosided Student's $t$ test.

Figures $7 \mathrm{~b}-\mathrm{e}$ show correlation maps (spatial patterns) of the predictions produced by the four models investigated here (CNRM, ECMWF, UKMO, and EMP). The spatial structure of these patterns when compared to the observed pattern (Fig. 7a) provides an indication of the ability of these models to reproduce the observed rainfall. The magnitude of the correlations in Figs. 7b-e gives an indication of the weights attributed to each model in the forecast assimilation procedure. The four models are able to reproduce the observed negative correlations over central-northern South America, although the area of negative correlations in the three coupled models is much larger than observed. The pattern of positive correlation in northwestern South America, near Ecuador, is captured by the ECMWF, UKMO, and EMP models, whereas CNRM fails to reproduce this feature. All four models are able to capture the sign of positive correlations in southern Brazil, Uruguay, Paraguay, and northern Argentina, although the location of the maximum corre- 
a) Observation

b) CNRM

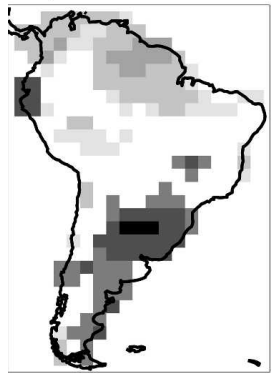

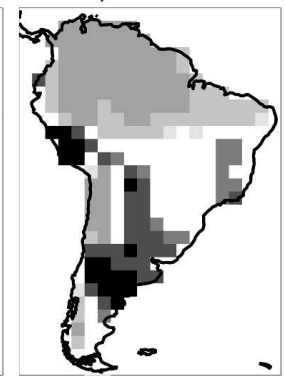

c) ECMWF

d) UKMO

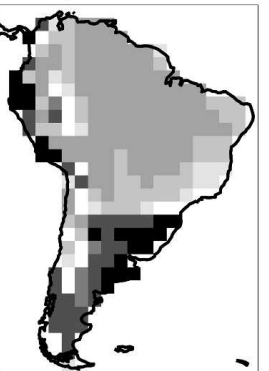

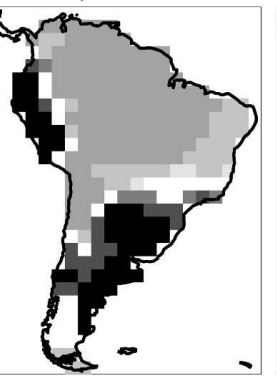

e) EMP
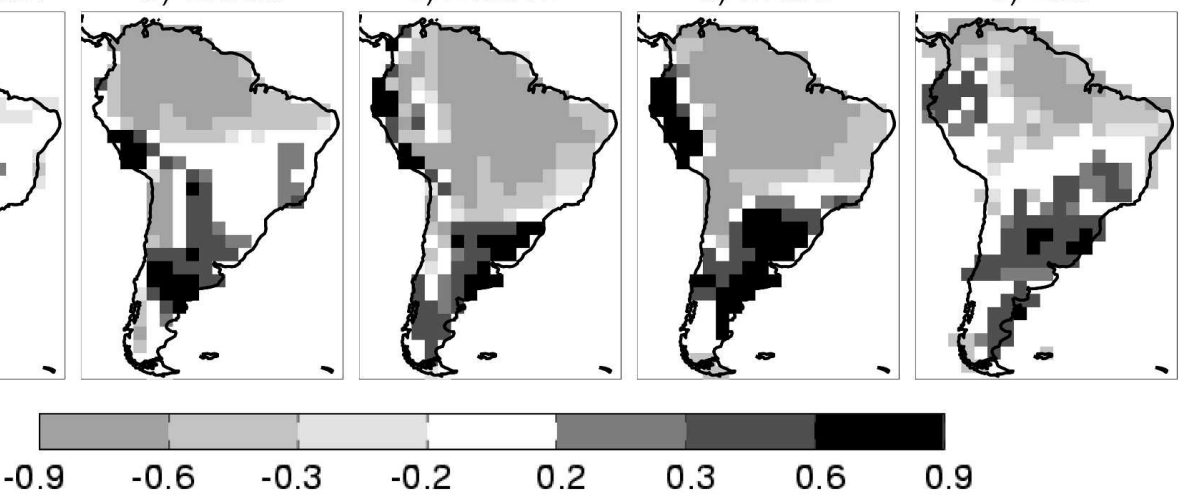

f) Time series $\quad r=0.87$

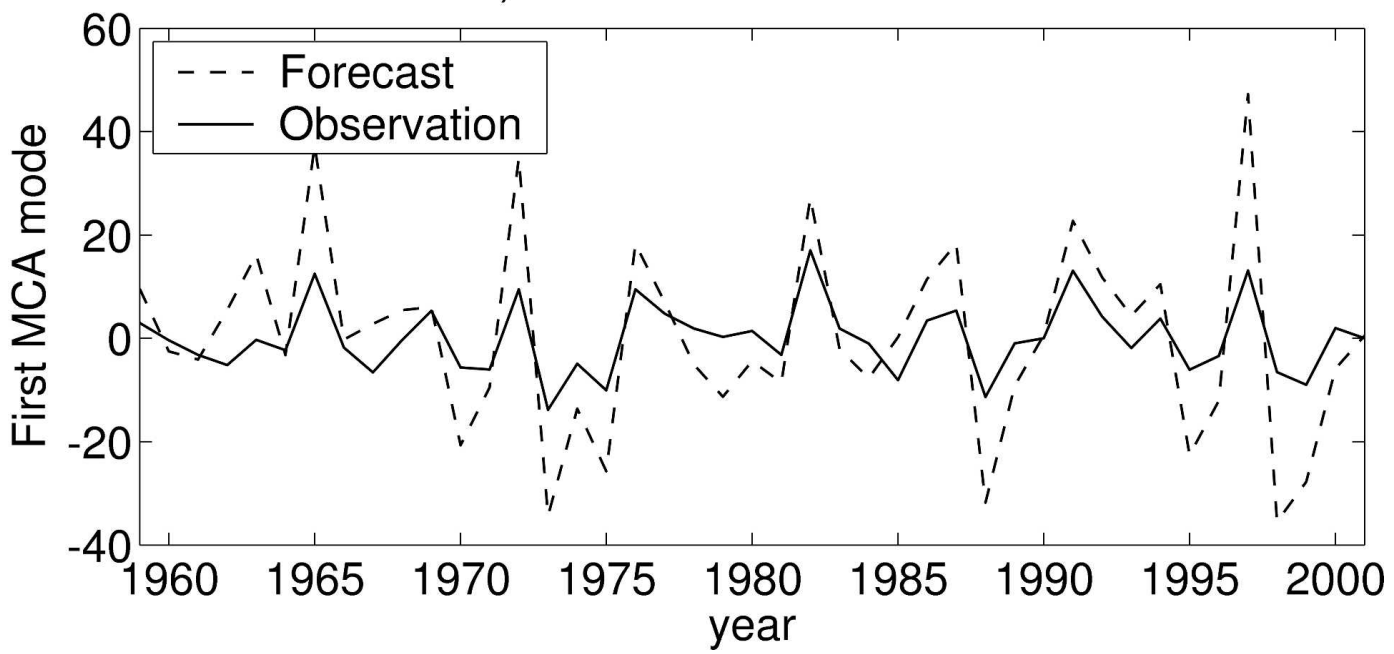

FIG. 7. Correlation patterns of the first MCA mode between observed and predicted austral summer South American rainfall anomalies for the period 1959-2001. The SCF is $77.7 \%$. (a) Observation, (b) CNRM, (c) ECMWF, (d) UKMO, (e) EMP, and (f) expansion coefficients (time series) of observed (solid line) and predicted (dashed line) rainfall of the four models. The correlation $r$ between these two time series is indicated in (f).

lation does not perfectly match the observations. The second and third MCA modes account for $6.2 \%$ and $3.9 \%$ of the squared covariance between observed and predicted rainfall, respectively, and do not resemble any previously published mode of climate variability (not shown).

\section{Forecast skill}

Figure 8 shows observed austral summer rainfall anomalies during 1982/83, 1988/89, and 1998/99 (Figs. $8 \mathrm{a}-\mathrm{c})$, and the forecast anomalies for these three years produced by the empirical model (Figs. 8d-f), the coupled multimodel ensemble (Figs. 8g-i), and the integrated system (Figs. 8j-1). These three examples show an El Niño episode (1982/83) and two La Niña episodes (1988/89 and 1998/99). El Niño and La Niña episodes have been chosen to illustrate how predictable the mean large-scale rainfall pattern is over South America during three distinct ENSO extreme conditions. The spatial correlation between the observed and the forecast anomalies is shown in the bottom right-hand corner in Figs. 8d-1. Note that spatial correlation is used here to easily compare and quantify forecast skill rather than check the statistical significance of different forecasting approaches. To obtain a more comprehensive view of forecast performance, in addition to the spatial correlation, forecast regional spatial patterns should also be compared to the observed regional spatial patterns. Empirical predictions are able to reproduce the observed pattern of negative anomalies in northern South America and positive anomalies in southern Brazil during 1982/83 (Fig. 8d) and a reverse pattern during 1988/89 (Fig. 8e). In 1998/99, the empirical model failed 
a) $1982 / 83$ (OBS)

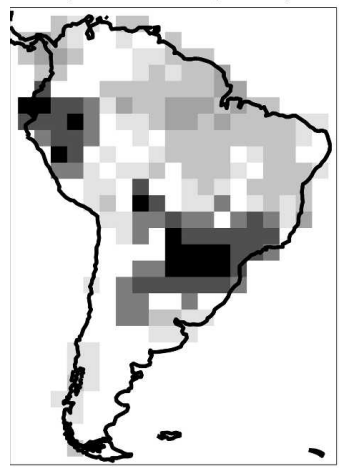

d) $1982 / 83$ (EMP)

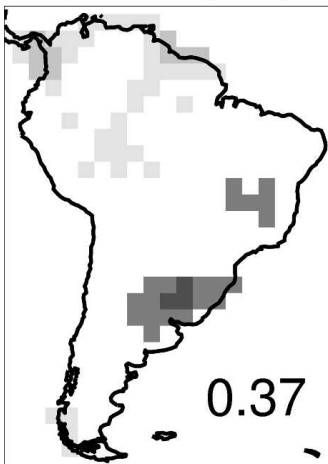

g) $1982 / 83$ (ENS)

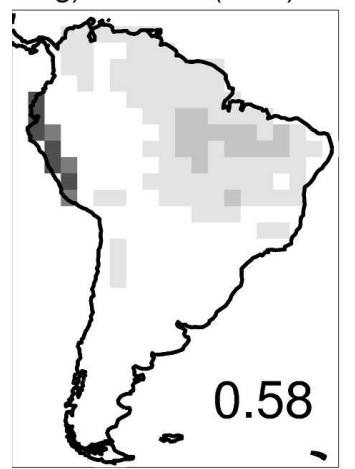

j) $1982 / 83$ (INT)

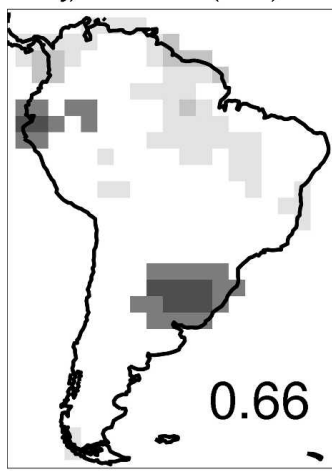

k) $1988 / 89$ (INT)
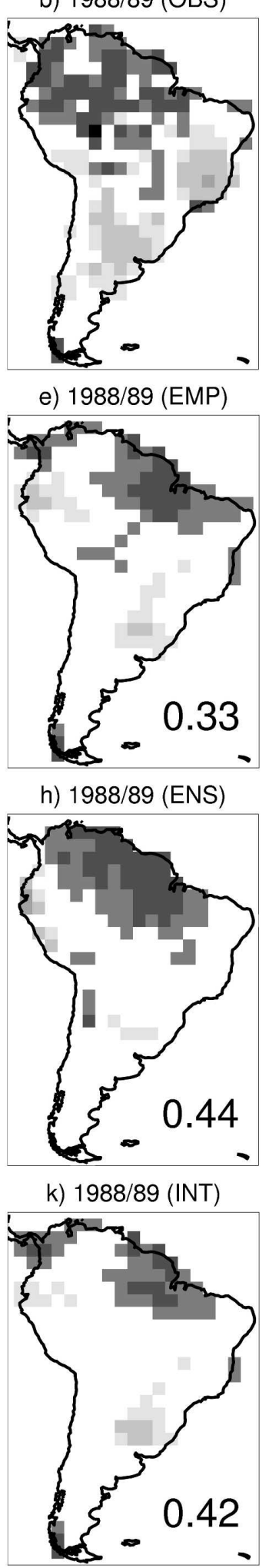

c) $1998 / 99$ (OBS)

e) $1988 / 89$ (EMP)

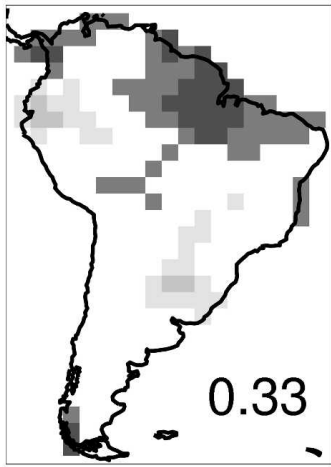

h) $1988 / 89$ (ENS)
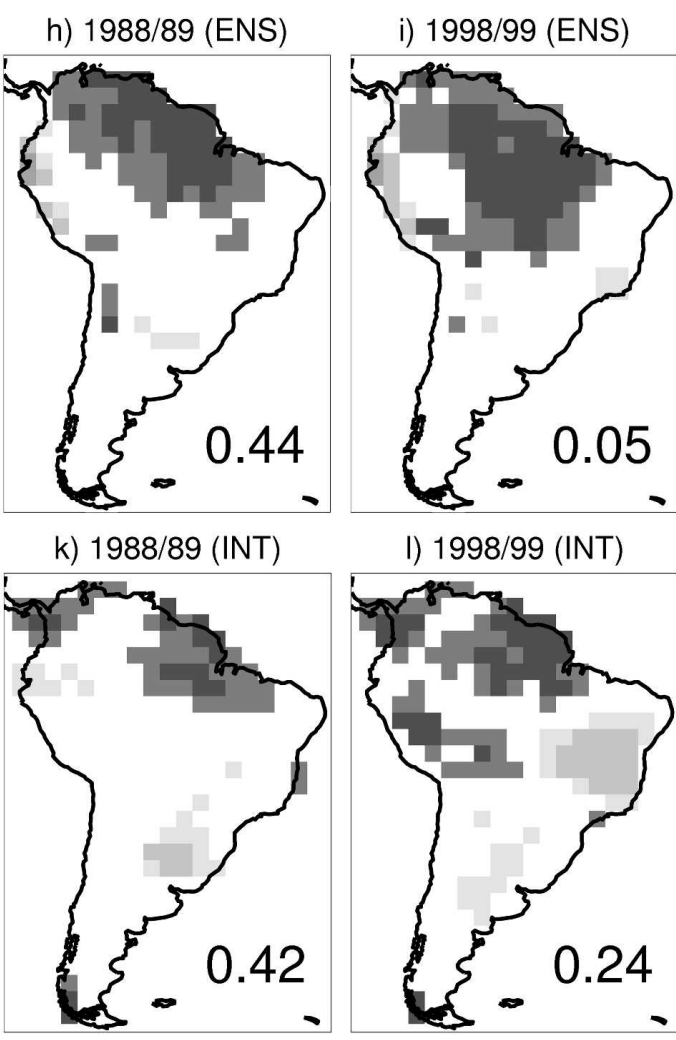

$$
-500-250-100 \quad-50 \quad 50 \quad 100 \quad 250 \quad 500
$$

FIG. 8. Austral summer rainfall anomalies (mm) for 1982/83, 1988/89, and 1998/99. (a)-(c) Observations, (d)-(f) empirical forecasts, (g)-(i) coupled multimodel ensemble forecasts, and (j)-(l) integrated forecasts. 
to successfully reproduce the observed pattern (Fig. 8f). The coupled multimodel prediction was able to reproduce the observed dipole pattern of negative anomalies in northern South America and positive anomalies in costal Peru and Ecuador during 1982/83, but failed to reproduce the pattern of positive anomalies observed in southern Brazil (Fig. 8g). In 1988/89, the coupled multimodel partially reproduced the observed pattern of positive anomalies in northern South America and negative anomalies in southern Brazil (Fig. 8h). In 1998/99, as for the empirical prediction (Fig. 8f), the coupled multimodel failed to reproduce the observed pattern (Fig. 8i). When empirical and coupled multimodel predictions were combined and calibrated with forecast assimilation, much better integrated forecasts were obtained. Integrated forecasts (Figs. 8j-1) are in better agreement with the observations (Figs. 8a-c). Integrated forecasts for 1982/83 have a spatial correlation of 0.66 (Fig. 8j), which is larger than the values of 0.37 and 0.58 obtained for empirical and coupled multimodel predictions, respectively (Figs. $8 \mathrm{~d}, \mathrm{~g}$ ). The integrated forecasts for 1988/89 have a spatial correlation of 0.42 (Fig. 8k), which is larger than the value of 0.33 for the empirical prediction (Fig. 8e) and slightly smaller that the value of 0.44 for the coupled multimodel prediction (Fig. 8h). Note, however, that the integrated forecast reproduces the observed negative anomalies in southern Brazil much better than the coupled multimodel prediction. Integrated forecasts for 1998/99 have a spatial correlation of 0.24 (Fig. 81), which is much larger than the values of 0.05 obtained for empirical and coupled multimodel predictions (Figs. 8f,i). The predictive skill of 1998/99 was much lower than 1982/83 and 1988/89.

Figure 9 shows maps of Brier score (Brier 1950), its reliability, and its uncertainty minus resolution components for empirical (Figs. 9a-c), multimodel (Figs. 9d -f), and integrated forecasts (Figs. 9g-i) for the period 1959-2001. See Wilks (1995, section 7.4.3) for further information about the Brier score and its decomposition. The sum of the reliability map (Figs. 9b,e,h) and the uncertainty minus resolution map (Figs. 9c,f,i) gives the Brier score map (Figs. 9a,d,g) for each of the three forecasts in Fig. 9. The Brier score is computed here for the binary event defined by negative seasonal mean rainfall anomalies. The Brier score is a negatively oriented measure of skill, meaning that smaller values indicate better forecast quality. Forecasts with a Brier score $<0.25$ are better than the climatological forecast of the event. Regions showing simultaneously small values of reliability and uncertainty minus resolution have better forecast skill. The tropical region (in northern South America) and the subtropics (southern Brazil,
Uruguay, Paraguay, and northern Argentina) are the most skillful regions, with Brier scores less than 0.25 (Figs. 9a,d,g). Interestingly, these two regions have the Yule-Kendall skewness statistics of rainfall anomalies closer to zero than the other regions of South America (Fig. 3). This suggests that forecast skill for the other regions of South America might be improved if another distribution, different from the multivariate normal distribution, is used in the forecast assimilation procedure. Figures 9a, 9d, and 9g suggest that most of the skill of South American rainfall predictions is ENSO derived, in accordance with Figs. 5 and 7, which show that most of the predictability of South American austral summer rainfall is ENSO related.

The comparison of Brier score maps in Figs. 9a and $9 \mathrm{~d}$ reveals that empirical and multimodel predictions have similar levels of skill. Integrated forecasts obtained with forecast assimilation have improved skill over both empirical and multimodel predictions alone (Fig. 9g). Integrated forecasts (Fig. 9g) have larger areas, with Brier scores below 0.25, than empirical (Fig. 9a) and multimodel (Fig. 9d) predictions. Integrated forecasts still show predictive skill over the south of the northeast regions of Brazil, whereas empirical and multimodel forecasts have poor predictive skill over these regions. The improved predictive skill obtained with the integrated system is mainly due to improvements in the reliability of the forecasts (Figs. 9b,e,h). Reliability refers to the correspondence between the forecast probability of an event and the relative frequency of the event conditioned upon the forecast probability (Jolliffe and Stephenson 2003). Reliability is a measure of forecast uncertainty correctness and assesses the calibration of the forecasts. Empirical (Fig. 9b) and multimodel (Fig. 9e) predictions have good (small) reliability in the Tropics and southeastern South America. In other words, empirical and multimodel predictions for these two regions are well calibrated. Integrated forecasts (Fig. 9h) have better (smaller) reliability than both empirical and multimodel predictions, not only in these two regions but also in northeastern South America, indicating that integrated forecasts are better calibrated than empirical and multimodel predictions. Improvements in the resolution of the forecasts are noticed in tropical South America and southern Brazil (Figs. 9c,f,i). Resolution summarizes the ability of the forecasting system to discriminate between different observed situations (Jolliffe and Stephenson 2003). The uncertainty minus resolution component of the Brier score shown in Figs. 9c, 9f, and 9i provides a quantitative measure of forecast resolution because the uncertainty component only depends on the observations and therefore is not influenced by the forecasts. Em- 
a) Brier score (EMP)

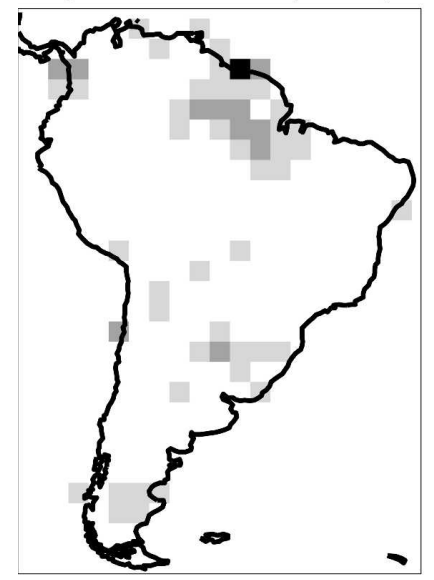

d) Brier score (ENS) b) Reliability (EMP)

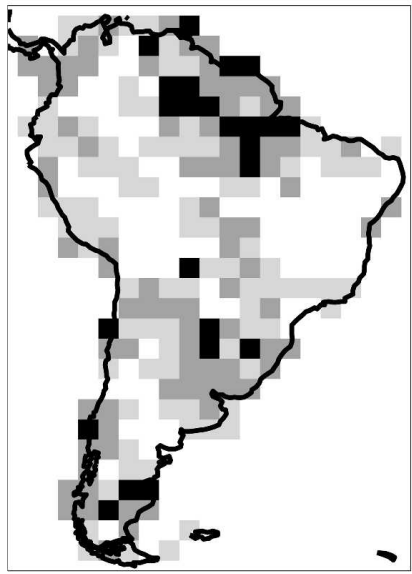

e) Reliability (ENS)
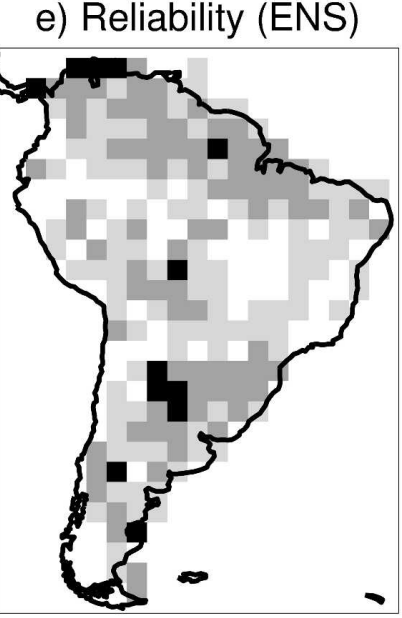

h) Reliability (INT)

c) Uncert-Resol (EMP)

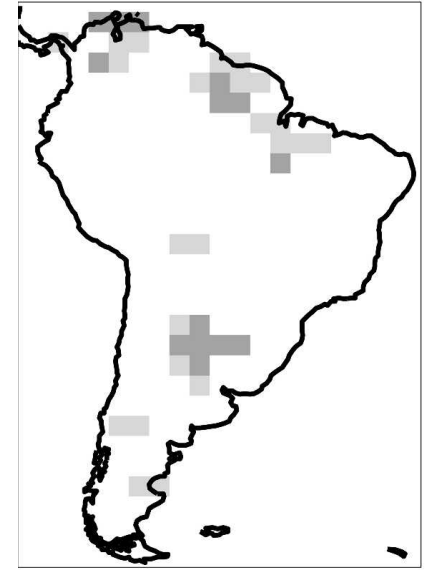

g) Brier score (INT)
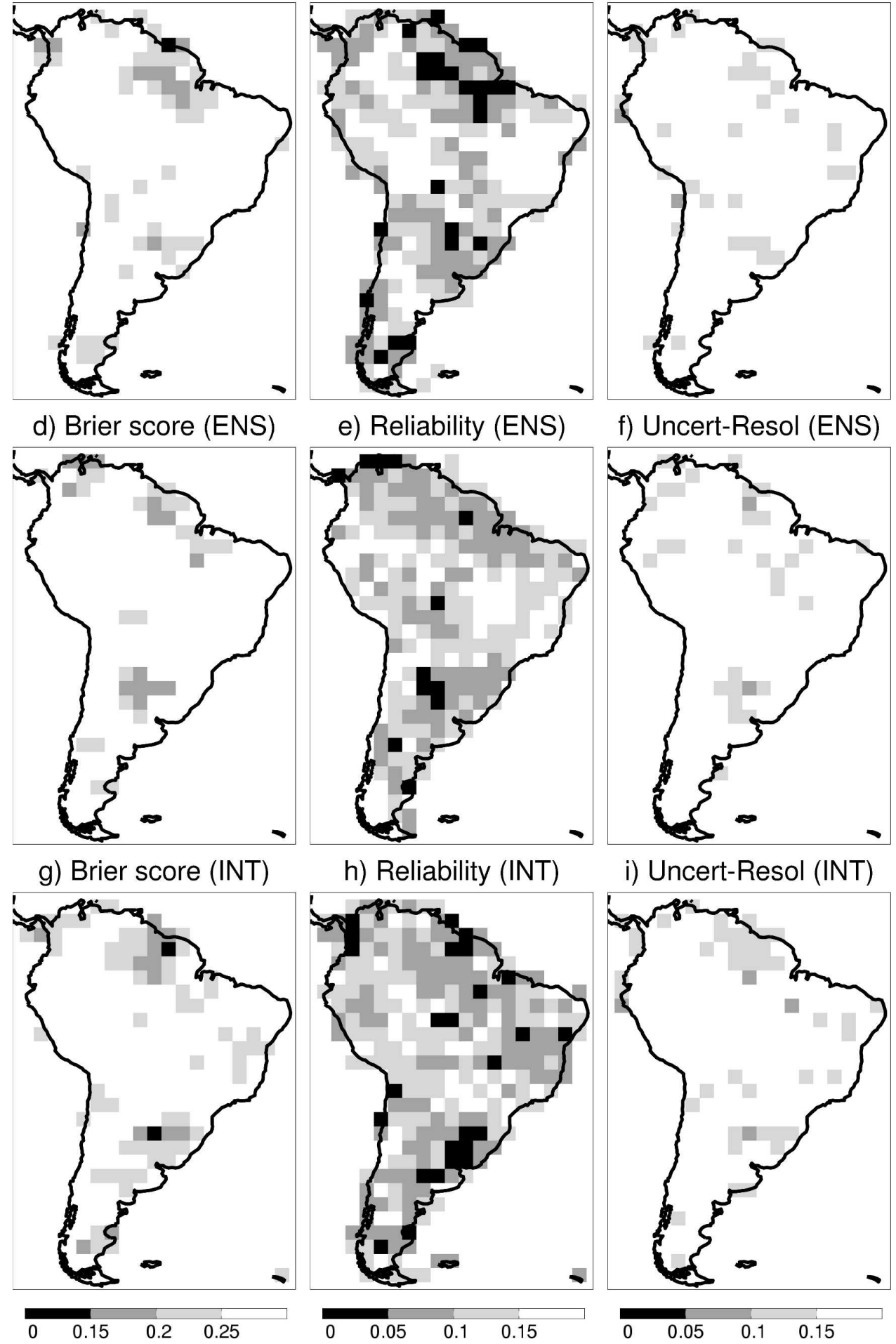

f) Uncert-Resol (ENS)

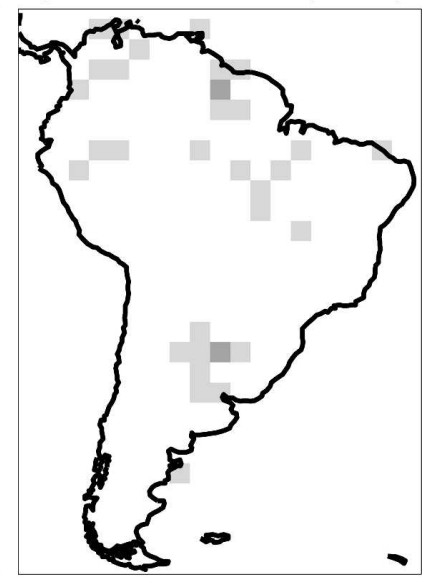

i) Uncert-Resol (INT)

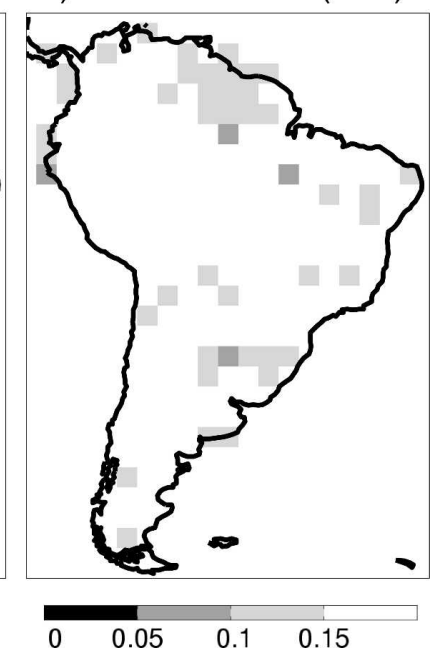

FIG. 9. (left) Brier scores for the binary event defined by negative seasonal mean rainfall anomalies and its (middle) reliability and (right) resolution components for (a)-(c) empirical, (d)-(f) ensemble, and (g)-(i) integrated forecasts. Brier scores are for austral summer forecasts for the period 1959-2001. The reliability and resolution components were estimated using 10 equally spaced probability bins from 0 to 1. 


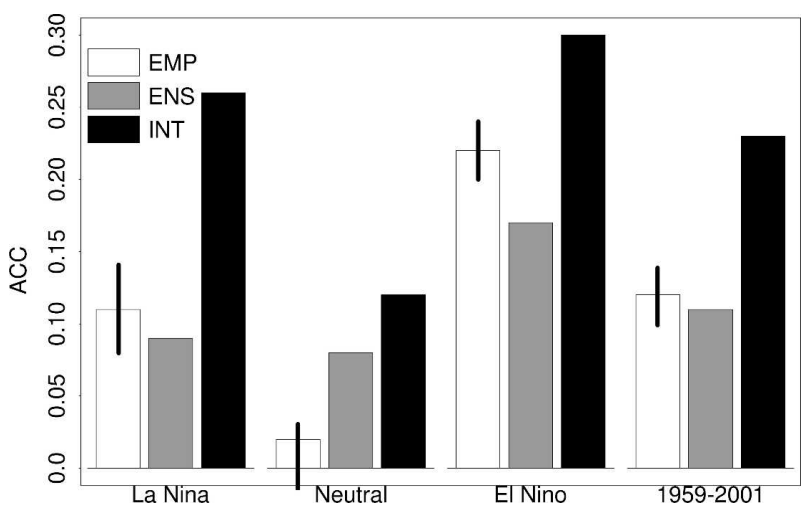

FIG. 10. Mean austral summer ACC for EMP, coupled multimodel ENS, and INT forecasts of La Niña, neutral, El Niño years (listed in Table 1), and all 1959-2001 years. The vertical solid lines on the top of the white bars indicate the $95 \%$ confidence interval for the mean ACC of empirical forecasts, which were obtained using a bootstrap resampling procedure (Wilks 1995, his section 5.3.2).

pirical (Fig. 9c) and multimodel (Fig. 9f) predictions have good (small) uncertainty minus resolution in tropical and southeastern South America. Integrated forecasts (Fig. 9i) have better (smaller) uncertainty minus resolution than empirical and multimodel predictions over both tropical and southeastern South America. Note that resolution improvements achieved here do not come from the calibration procedure but instead result from the combination of three different coupled model ensemble predictions.

Figure 10 shows the mean anomaly correlation coefficient (ACC) for La Niña, neutral, and El Niño years occurring during 1959-2001 (listed in Table 1) and all (1959-2001) years. The ACC of each year is given by the correlation between the observed and predicted spatial anomaly pattern (Jolliffe and Stephenson 2003, their section 6.3.1). The most striking feature in Fig. 10 is the small magnitude of the mean ACC (inferior to 0.3), illustrating that austral summer South American rainfall forecast skill is low. La Niña and El Niño years have higher mean ACC than neutral years, indicating that predictions for ENSO years are more skillful than predictions for neutral years. Note, however, that predictions for El Niño years are more skillful than predictions for La Niña years. El Niño and La Niña integrated forecasts obtained with forecast assimilation show an increase in the mean ACC compared to empirical and multimodel predictions. This is because forecast assimilation has shifted model predicted patterns toward observed patterns. Neutral years have very little mean ACC, indicating that rainfall anomalies for these years are hardly predicted. The higher predictability of ENSO years compared to neutral years supports the argument that most of the skill of austral summer South American rainfall forecasts is ENSO derived. The vertical solid lines on the top of the white bars in Fig. 10 indicate the 95\% confidence interval for the mean ACC of empirical predictions. These intervals were obtained using a bootstrap resampling procedure as described in Wilks (1995, section 5.3.2). Mean ACCs that are within the range of values of the $95 \%$ confidence interval for the mean ACC of empirical predictions cannot be considered different from the mean ACC of empirical predictions from the statistical point of view at the $5 \%$ significance level. This means that empirical and multimodel predictions have similar levels of skill when forecasting the rainfall of La Niña years and throughout all (1959-2001) years.

\section{Conclusions}

This study has addressed the predictability of austral summer mean South American rainfall by proposing an integrated seasonal forecasting system for South America. The proposed integrated system has two components: (i) an empirical model that uses Pacific and Atlantic sea surface temperature anomalies as predictors for South American rainfall and (ii) a multimodel coupled system composed of the ECMWF, CNRM, and UKMO models. These models constitute the operational European multimodel seasonal forecasting system, which is hosted at ECMWF. Empirical and coupled model predictions were combined and calibrated using a Bayesian forecast assimilation procedure

TABle 1. La Niña, neutral, and El Niño years occurring during 1959-2001 as defined by the Climate Prediction Center (CPC; see online at http://www.cpc.noaa.gov/). CPC designates La Niña episodes when the 3-month running mean of SST anomalies (based on the $1971-2000$ period) in the Niño-3.4 region $\left(5^{\circ} \mathrm{N}-5^{\circ} \mathrm{S}, 120^{\circ}-170^{\circ} \mathrm{W}\right)$ is below $0.5^{\circ} \mathrm{C}$ for a minimum of five consecutive overlapping seasons and El Niño episodes when the SST is above $0.5^{\circ} \mathrm{C}$. Neutral episodes are the remaining years.

Year

La Niña 1964/65, 1970/71, 1971/72, 1973/74, 1974/75, 1975/76, 1983/84, 1984/85, 1988/89, 1995/96, 1998/99, 1999/00, 2000/01

Neutral 1959/60, 1960/61, 1961/62, 1962/63, 1966/67, 1967/68, 1978/79, 1980/81, 1981/82, 1985/86, 1989/90, 1993/94, 1996/97, 2001/02

El Niño 1963/64, 1965/66, 1968/69, 1969/70, 1972/73, 1976/77, 1977/78, 1979/80, 1982/83, 1986/87, 1987/88, 1990/91, 1991/92, 1992/93, 1994/95, 1997/98 
(Coelho 2005; Stephenson et al. 2005) in order to produce a single integrated probabilistic forecast. The objective calibration and combination of empirical and multimodel coupled predictions proposed here makes this a first step toward an integrated forecasting system for issuing South American seasonal forecasts.

The proposed integrated system could feasibly be implemented at any operational weather service in South America [e.g., the Center for Weather Prediction and Climate Studies (CPTEC) in Brazil]. The proposed system can be expanded by the inclusion of CPTEC coupled model predictions in addition to the ECMWF, CNRM, and UKMO coupled model predictions in the multimodel system. However, the feasibility of the implementation of such a new system depends on the establishment of international cooperation between CPTEC, ECMWF, CNRM, and UKMO, as well as other South American weather services. The initial steps for this implementation have been given with the approval of the European-Brazilian Initiative for Improving South American Seasonal Forecasts (EUROBRISA) project (available online at http://www.met.reading. ac.uk/ swr01cac/EUROBRISA) proposal by ECMWF council members in June 2005. As part of this project, ECMWF, CNRM, UKMO, and CPTEC will produce real-time seasonal forecasts, which will be integrated using the Bayesian forecast assimilation procedure to produce a well-calibrated probabilistic forecast for South America. A number of governmental activities that depend on seasonal forecast information (e.g., electricity generation and agriculture) are planned within EUROBRISA. Such a system could be used as an additional tool for producing objective probabilistic climate forecasts during regional climate outlook forums, which are regularly sponsored by the World Meteorological Organization. A similar approach could be of use in other regions of the world (e.g., North America).

To answer the question of whether or not forecasts produced by the proposed integrated system are better than those produced by a simple empirical model or by the simple multimodel ensemble alone, the skill of empirical, coupled multimodel, and integrated forecasts obtained with forecast assimilation has been assessed and compared. This comparison revealed that when seasonally forecasting South American austral summer rainfall at a 3-month lead time, the current generation of coupled models has a comparable level of skill to that obtained using a simplified empirical approach. The same conclusion holds for shorter (e.g., 1 month) lead times (Coelho et al. 2005). This result is in agreement with the findings of previous comparison studies (e.g., Folland et al. 2001; Moura and Hastenrath 2004), implying that both empirical and coupled model predictions are comparable to each other. However, when empirical and coupled multimodel forecasts have been combined and calibrated with forecast assimilation, more skillful integrated forecasts than either empirical or coupled multimodel predictions alone have been obtained. This result demonstrates that forecast assimilation can be used for improving the quality of South American seasonal predictions. The resulting integrated forecasts have been shown to possess improved Brier scores compared to both empirical and the simple multimodel predictions over several regions of South America. Forecast assimilation improved both the reliability and resolution of the predictions in tropical South America. Southeastern South America-an important region for South American hydroelectricity and crop yield production - and the northeast region of Brazil also had the reliability of the predictions improved. Recent results demonstrate that forecast assimilation is also useful for the downscaling of regional rainfall and river flow anomalies for northern and southeastern South America (Coelho et al. 2006).

The Tropics and southern Brazil, Uruguay, Paraguay, and northern Argentina have been found to be the two most predictable regions of South America. South American rainfall is generally only predictable in ENSO years rather than in neutral years, which exhibit very little skill. The skill of austral summer South American rainfall predictions produced with the current generation of coupled and empirical models is still low (cf. values of mean ACC are less than 0.3). This suggests that a large amount of research is still required in order to improve the quality of these predictions. It is well known that teleconnection patterns are sensitive to model resolution, treatment of boundary layer processes, and convection parameterization, but more research is needed to precisely identify which particular aspect or combination of aspects are responsible for the poor forecast skill and therefore need to be improved.

It would be interesting in the future to extend forecast assimilation to nonnormally distributed data and to deal with weather and climate extremes. The use of nonnormal distributions might improve forecast skill over those regions of South America where the normality assumption is not strictly valid. The nonstationarity of climate can also affect forecast calibration. The development of more generalized methods capable of dealing with nonstationary time series might also help to improve forecast skill. Model selection prior to the combination of predictions might also help to improve forecast skill. 
Acknowledgments. We wish to thank Prof. D. L. T. Anderson and Dr. T. N. Palmer, who kindly provided the ECMWF coupled model hindcasts used in this research. CASC was sponsored by Conselho Nacional de Desenvolvimento Científico e Tecnológico (CNPq) Process 200826/00-0. FJDR was supported by DEMETER (EVK2-1999-00024).

\section{APPENDIX}

\section{Bayesian Forecast Assimilation}

Forecast assimilation (Coelho 2005; Stephenson et al. 2005 ) is based upon Bayesian updating of prior information when new information becomes available (Bayes 1763). If one has a first guess of the prior distribution $p(y)$ of a particular variable of forecast interest $y$ (e.g., rainfall) and additional (new) prediction information $x$ then becomes available (e.g., an ensemble of predictions), then it is possible to update $p(y)$ to obtain the posterior conditioned probability density function $p(y \mid x)$ by making use of Bayes' theorem

$$
p(y \mid x)=\frac{p(y) p(x \mid y)}{p(x)} .
$$

The distribution of climate model ensemble predictions gives an estimate of $p(x)$. However, one is really interested in the posterior distribution $p(y \mid x)$, not $p(x)$. Because of uncertainties in model formulation and in initial conditions, climate predictions in model space deviate away from the true evolution in observation space. Model predictions $x$ should then be considered as proxy information that can be used to infer the probability of future observables $y$ (Glahn 2004; Stephenson et al. 2005; Jolliffe and Stephenson 2005). To make inferences about future observables, one needs a probability model that can give the probability $p(y \mid x)$ of future observable quantities $y$ when provided with model prediction data $x$, such as the model of Eq. (A1).

The likelihood $p(x \mid y)$ is an essential ingredient in the Bayesian forecast assimilation updating procedure. It can easily be estimated by the regression of past model predictions $x$ on past observations $y$. However, as for the empirical model of section $3 \mathrm{a}$, because of the large dimensionality of gridded datasets compared to the number of independent forecasts and the dependency between values at neighboring grid points, the multivariate linear regression of a few MCA leading modes is applied.

As described in Coelho et al. (2003, 2004), Coelho (2005), and Stephenson et al. (2005), the Bayesian procedure used to perform forecast assimilation has three main ingredients: (i) estimation of the prior distribution $p(y)$, (ii) modeling of the likelihood function $p(x \mid y)$, and (iii) use of Bayes' theorem to find the posterior distribution $p(y \mid x)$ from $p(x)$ and $p(x \mid y)$. For simplicity, it has been assumed that both prior and likelihood distributions are multivariate normal (Gaussian), leading to a multivariate normal posterior distribution. Analysis of skewness $\gamma$ reveals that this assumption is generally acceptable for observed and predicted South American seasonal rainfall anomalies. Several regions of South America have observed and predicted seasonal rainfall skewness close to zero and therefore are not very far from following a normal distribution (Fig. 3).

The full equations of the multivariate normal model used here to perform Bayesian forecast assimilation are given in Coelho (2005) and Stephenson et al. (2005). All results presented here were obtained with the crossvalidation "leave one out" method (Wilks 1995, his section 6.3.6).

Three different forecast assimilation experiments have been produced:

- Integrated forecasts produced with prior distribution $p(y)$ (estimated using rainfall observations over the calibration period 1959-2001) and using empirical predictions in addition to coupled model predictions in the forecast assimilation procedure. In other words, the matrix of forecasts used in forecast as similation consisted of predictions of the CNRM, ECMWF, and UKMO coupled models in addition to empirical model predictions.

- Integrated forecasts with empirical prior distribution produced with empirical predictions as estimates of the prior distribution $p(y)$; only the CNRM, ECMWF, and UKMO predictions are used in the forecast assimilation procedure.

- Coupled model integrated forecasts produced with prior distribution estimated using rainfall observations over the calibration period 1959-2001; only the CNRM, ECMWF, and UKMO predictions are used in the forecast assimilation procedure. These forecasts do not incorporate empirical predictions.

The second and third experiments above have been performed as sensitivity tests for the first experiment. The second experiment was designed to check whether or not the use of empirical predictions as estimates for the prior distribution could provide better quality forecasts than the integrated forecasts of the first experiment. The third experiment aimed to check if the exclusion of empirical predictions in the first experiment would impact the gain or loss of forecast skill. Results indicate that integrated forecasts obtained in the first experiment have slightly more skill than the forecasts of 
the other two experiments. For this reason, only integrated forecasts of the first experiment are shown and discussed. These forecasts are referred to as INT.

Finally, it is noteworthy that forecast assimilation has some advantages (e.g., it produces well-calibrated probability forecasts, is able to deal with ensemble predictions and multimodel predictions, preserves spatial structure present in the datasets, and allows spatial patterns to be shifted/corrected) and some potential disadvantages [e.g., it needs data reduction for the estimation of regression parameters, the relationships can change with time (stability), and the calibration equations (regression) need to be recomputed each time the forecasting system changes].

\section{REFERENCES}

Anderson, J. L., H. Van den Dool, A. Barnston, W. Chen, W. Stern, and J. Ploshay, 1999: Present-day capabilities of numerical and statistical models for atmospheric extratropical seasonal simulation and prediction. Bull. Amer. Meteor. Soc., 80, 1349-1361.

Barnston, A. G., M. H. Glantz, and Y. He, 1999: Predictive skill of statistical and dynamical climate models in SST forecasts during the 1997-98 El Niño episode and the 1998 La Niña onset. Bull. Amer. Meteor. Soc., 80, 217-243.

— , S. J. Mason, L. Goddard, D. G. DeWitt, and S. E. Zebiak, 2003: Multimodel ensembling in seasonal climate forecasting at IRI. Bull. Amer. Meteor. Soc., 84, 1783-1796.

Barros, V. R., and G. E. Silvestri, 2002: The relation between sea surface temperature at the subtropical south-central Pacific and precipitation in southeastern South America. J. Climate, 15, 251-267.

Bayes, T., 1763: An essay towards solving a problem in the doctrine of chances. Philos. Trans. Roy. Soc. London, 53, 370418.

Berri, G. J., and P. L. Antico, 2005: Seasonal precipitation forecasts for the southeast of South America. Evaluating the first five years. CLIVAR Exchanges, No. 10, International CLIVAR Project Office, Southampton, United Kingdom, 25-27.

Brier, G. W., 1950: Verification of forecasts expressed in terms of probability. Mon. Wea. Rev., 78, 1-3.

Cavalcanti, I. F. A., and Coauthors, 2002: Global climatological features in a simulation using the CPTEC-COLA AGCM. $J$. Climate, 15, 2965-2988.

Chen, M., P. Xie, J. E. Janowiak, and P. A. Arkin, 2002: Global land precipitation: A 50-yr monthly analysis based on gauge observations. J. Hydrometeor., 3, 249-266.

Coelho, C. A. S., 2005: Forecast calibration and combination: Bayesian assimilation of seasonal climate predictions. Ph.D. thesis, University of Reading, 178 pp.

— C. B. Uvo, and T. Ambrizzi, 2002: Exploring the impacts of the tropical Pacific SST on the precipitation patterns over South America during ENSO periods. Theor. Appl. Climatol., 71, 185-197.

— S. Pezzulli, M. Balmaseda, F. J. Doblas-Reyes, and D. B. Stephenson, 2003: Skill of coupled model seasonal forecasts: A Bayesian assessment of ECMWF ENSO forecasts. Euro- pean Centre for Medium-Range Weather Forecasts Tech. Memo. 426, 16 pp.

,,,,---- and,- 2004 : Forecast calibration and combination: A simple Bayesian approach for ENSO. J. Climate, 17, 1504-1516.

- D. B. Stephenson, F. J. Doblas-Reyes, and M. Balmaseda, 2005: From multi-model ensemble predictions to wellcalibrated probability forecasts: Seasonal rainfall forecasts over South America 1959-2001. CLIVAR Exchanges, No. 10, International CLIVAR Project Office, Southampton, United Kingdom, 14-20.

,,,--- A. Guetter, and G. J. van Oldenborgh, 2006: A Bayesian approach for multi-model downscaling: Seasonal forecasting of regional rainfall and river flows in South America. Meteor. Appl., 13, 73-82.

Diaz, A. F., C. D. Studzinski, and C. R. Mechoso, 1998: Relationships between precipitation anomalies in Uruguay and Southern Brazil and sea surface temperature in the Pacific and Atlantic Oceans. J. Climate, 11, 251-271.

Folland, C. K., A. W. Colman, D. P. Rowell, and M. K. Davey, 2001: Predictability of northeast Brazil rainfall and real-time forecast skill, 1987-98. J. Climate, 14, 1937-1958.

Glahn, B., 2004: Discussion of verification concepts in Forecast Verification: A Practitioner's Guide in Atmospheric Science. Wea. Forecasting, 19, 769-775.

Greischar, L., and S. Hastenrath, 2000: The rainy seasons of the 1990s in northeast Brazil: Real-time forecasts and verification. J. Climate, 13, 3821-3826.

Hagedorn, R., F. J. Doblas-Reyes, and T. N. Palmer, 2005: The rationale behind the success of multi-model ensembles in seasonal forecasting. Part I: Basic concept. Tellus, 57, 219-233.

Huffman, G. J., R. F. Adler, A. Chang, R. Ferraro, A. Gruber, A. McNab, B. Rudolf, and U. Schneider, 1997: The Global Precipitation Climatology Project (GPCP) combined precipitation dataset. Bull. Amer. Meteor. Soc., 78, 5-20.

Jolliffe, I. T., and D. B. Stephenson, Eds., 2003: Forecast Verification: A Practitioner's Guide in Atmospheric Science. Wiley and Sons, $240 \mathrm{pp}$.

$\longrightarrow$, and - 2005: Comments on "Discussion of verification concepts in Forecast Verification: A Practitioner's Guide in Atmospheric Science." Wea. Forecasting, 20, 796-800.

Kiladis, G. N., and H.F. Diaz, 1989: Global climate anomalies associated with extremes in the Southern Oscillation. J. Climate, 2, 1069-1090.

Marengo, J. A., and Coauthors, 2003: Assessment of regional seasonal rainfall predictability using the CPTEC/COLA atmospheric GCM. Climate Dyn., 21, 459-475.

Martis, A., G. J. van Oldenborgh, and G. Burgers, 2002: Predicting rainfall in the Dutch Caribbean-more than El Niño. Int. J. Climatol., 22, 1219-1234.

Mason, S. J., and G. M. Mimmack, 2002: Comparison of some statistical methods of probabilistic forecasting of ENSO. $J$. Climate, 15, 8-29.

Mechoso, C. R., S. W. Lyons, and J. A. Spahr, 1990: The impact of sea surface temperature anomalies on the rainfall over northeast Brazil. J. Climate, 3, 812-826.

Moura, A. D., and J. Shukla, 1981: On the dynamics of droughts in northeast Brazil: Observations, theory and numerical experiments with general circulation model. J. Atmos. Sci., 38, 2653-2675.

_ Nordeste: Performance of empirical and numerical modeling methods. J. Climate, 17, 2667-2672. 
Nobre, P., and J. Shukla, 1996: Variations of sea surface temperature, wind stress, and rainfall over the tropical Atlantic and South America. J. Climate, 9, 2464-2479.

Paegle, J. N., and K. C. Mo, 2002: Linkages between summer rainfall variability over South America and sea surface temperature anomalies. J. Climate, 15, 1389-1407.

Palmer, T. N., and Coauthors, 2004: Development of a European Multimodel Ensemble System for Seasonal to Interannual Prediction (DEMETER). Bull. Amer. Meteor. Soc., 85, 853872 .

Pezzi, L., V. Ubarana, and C. Repelli, 2000: Forecast and performance of a statistical regional model for seasonal climate prediction in Southern Brazil. Rev. Bras. Geocien., 18, 129146.

Rajagopalan, B., U. Lall, and S. E. Zebiak, 2002: Categorical climate forecasts through regularization and optimal combination of multiple GCM ensembles. Mon. Wea. Rev., 130, 17921811.

Robertson, A. W., L. Upmanu, S. E. Zebiak, and L. Goddard, 2004: Improved combination of multiple atmospheric GCM ensembles for seasonal prediction. Mon. Wea. Rev., 132, 2732-2744.

Ropelewski, C. F., and M. S. Halpert, 1987: Global and regional scale precipitation patterns associated with El Niño/ Southern Oscillation. Mon. Wea. Rev., 115, 1606-1626.

Stephenson, D. B., C. A. S. Coelho, F. J. Doblas-Reyes, and M.
Balmaseda, 2005: Forecast assimilation: A unified framework for the combination of multi-model weather and climate predictions. Tellus, 57, 253-264.

Trenberth, K. E., G. W. Branstator, D. Karoly, A. Kumar, N.-C. Lau, and C. Ropelewski, 1998: Progress during TOGA in understanding and modeling global teleconnections associated with tropical sea surface temperatures. J. Geophys. Res., 103, 14 291-14 324.

Uppala, S. M., and Coauthors, 2005: The ERA-40 Re-analysis. Quart. J. Roy. Meteor. Soc., 131, 2961-3012.

Uvo, C. B., C. A. Repelli, S. E. Zebiak, and Y. Kushnir, 1998: The relationships between tropical Pacific and Atlantic SST and northeast Brazil monthly precipitation. J. Climate, 11, 551562 .

van Oldenborgh, G. J., M. A. Balmaseda, L. Ferranti, T. N. Stockdale, and D. L. T. Anderson, 2005: Did the ECMWF seasonal forecast model outperform a statistical model over the last 15 years? J. Climate, 18, 2970-2989.

von Storch, H., and F. W. Zwiers, 1999: Statistical Analysis in Climate Research. Cambridge University Press, 484 pp.

Wallace, J. M., and D. S. Gutzler, 1981: Teleconnections in the geopotential height field during the Northern Hemisphere winter. Mon. Wea. Rev., 109, 785-812.

Wilks, D. S., 1995: Statistical Methods in the Atmospheric Sciences: An Introduction. Academic Press, 467 pp. 